\title{
Chitosan nanoparticle-based delivery of fused NKG2D-IL-2I gene suppresses colon cancer growth in mice
}

This article was published in the following Dove Press journal:

International Journal of Nanomedicine

I3 April 2017

Number of times this article has been viewed

\author{
Lunmei Tan' \\ Sen $\mathrm{Han}^{2}$ \\ Shizhen Ding ${ }^{2}$ \\ Weiming $\mathrm{Xiao}^{3,4}$ \\ Yanbing Ding ${ }^{3}$ \\ Li Qian ${ }^{2,4}$ \\ Chenming Wang ${ }^{1,5}$ \\ Weijuan Gong ${ }^{1-5}$
}

'Jiangsu Co-innovation Center for Prevention and Control of Important Animal Infectious Diseases and Zoonoses, ${ }^{2}$ Department of Immunology, School of Medicine, ${ }^{3}$ Department of Gastroenterology, The Second Clinical Medical College, ${ }^{4}$ Department of Integrated Chinese and Western Medicine, School of Medicine, ${ }^{5}$ Jiangsu Key Laboratory of Zoonosis, Yangzhou University, Yangzhou, People's Republic of China
Abstract: Nanoparticles can be loaded with exogenous DNA for the potential expression of cytokines with immune-stimulatory function. NKG2D identifies major histocompatibility complex class I chain-related protein in human and retinoic acid early induced transcript- 1 in mouse, which acts as tumor-associated antigens. Biologic agents based on interleukin 21 (IL-21) have displayed antitumor activities through lymphocyte activation. The NKG2D-IL-21 fusion protein theoretically identifies tumor cells through NKG2D moiety and activates T cells through IL-21 moiety. In this study, double-gene fragments that encode the extracellular domains of NKG2D and IL-21 genes were connected and then inserted into the pcDNA3.1(-) plasmid. PcDNA3.1-dsNKG2D-IL-21 plasmid nanoparticles based on chitosan were generated. Tumor cells pretransfected with dsNKG2D-IL-21 gene nanoparticles can activate natural killer (NK) and $\mathrm{CD}^{+} \mathrm{T}$ cells in vitro. Serum IL-21 levels were enhanced in mice intramuscularly injected with the gene nanoparticles. DsNKG2D-IL-21 gene nanoparticles accumulated in tumor tissues after being intravenously injected for $\sim 4-24 \mathrm{~h}$. Treatment of dsNKG2D-IL-21 gene nanoparticles also retarded tumor growth and elongated the life span of tumor-bearing mice by activating NK and T cells in vivo. Thus, the dsNKG2D-IL-21 gene nanoparticles exerted efficient antitumor activities and would be potentially used for tumor therapy.

Keywords: NKG2D, IL-21, fusion gene, cancer, chitosan nanoparticle

\section{Introduction}

Interleukin 2 (IL-2) family cytokine has attracted considerable research for cancer immunotherapy. ${ }^{1}$ IL-2 1 is a type I cytokine with molecular weight of $15 \mathrm{kDa}$. CD4 ${ }^{+}$ T cells include Th17, follicular helper T, and natural killer T (NKT) cells and secrete IL-21. IL-21 not only has stimulatory effects on cellular activation, trafficking, cell cycle progression, and cell survival but also plays a positive feedback of its own expression. Biologic agents based on IL-21 have been developed to suppress tumor growth. ${ }^{2,3}$

IL-21R is a heterodimer consisting of IL-21R $\alpha$ and common $\gamma$ chain. IL-2 1 receptor (IL-21R) is expressed by lymphoid cells (eg, B cells, T cells, NKT cells, and natural killer [NK] cells) and myeloid cells (eg, macrophages and dendritic cells). IL-21R is also expressed by nonimmune cells, such as intestinal fibroblasts and keratinocytes. ${ }^{4,5}$ IL-21R signaling induces the activation of Jak1, Jak3, STAT1, STAT3, STAT5, PI3K, and mitogen-activated protein kinase proteins. Lymphocytes could upregulate the cellular expression of granzyme A/B, perforin, IFN- $\gamma$, CXCR3, CXCR6, cyclins, IL-21, and IL-21R by IL-21 stimulation. Hence, the usage of IL-21-based agents in vivo could antagonize tumor growth through comprehensive activation of lymphocytes. ${ }^{6}$
Correspondence: Weijuan Gong Jiangsu Co-innovation Center for Prevention and Control of Important Animal Infectious Diseases and Zoonoses, Yangzhou University, Huaihai Road II Yangzhou, Jiangsu Province, People's Republic of China

Tel +865 I 487978820

Fax +865I48734 I733

Email wjgong@yzu.edu.cn hy ${ }_{\mathrm{NC}}$ and incorporate the Creative Commons Attribution - Non Commercial (unported, v3.0) License (http://creativecommons.org/licenses/by-nc/3.0/). By accessing the work you
hereby accept the Terms. Non-commercial uses of the work are permitted without any further permission from Dove Medical Press Limited, provided the work is properly attributed. For permission for commercial use of this work, please see paragraphs 4.2 and 5 of our Terms (https://www.dovepress.com/terms.php). 
NKG2D is a C-type lectin-like activating receptor, which is widely expressed by NK, NKT, $\mathrm{CD}^{+} \mathrm{T}$, and $\gamma \delta \mathrm{T}$ cells. Mouse NKG2D ligands consist of retinoic acid early induced transcript-1 (RAE-1), H60, and murine UL-16 binding protein (ULBP)-like transcript 1 . Human NKG2D can bind to the major histocompatibility complex class I chain-related protein A and ULBPs. NKG2D ligands are induced to obtain expression by virus-infected or tumor cells, but they are generally absent in most normal tissues; as such, these ligands serve as tumor-targeted antigens in immunotherapy. ${ }^{7,8}$

Chitosan nanoparticles are biodegradable, nontoxic carriers for nucleotides and drugs with potentiality for broad applications in human diseases. ${ }^{9}$ In this study, we aimed to construct chitosan-based nanoparticles to deliver a new jointed gene, named dsNKG2D-IL-21. The dsNKG2DIL-21 fusion gene includes double extracellular NKG2D gene domains and IL-21 gene. The dsNKG2D-IL-21 protein expressed by cells transfected with the nanoparticles would bridge tumor cells and lymphocytes through recognition of NKG2D ligands and IL-21R simultaneously. The use of the dsNKG2D-IL-21 gene chitosan nanoparticles in vivo would not only enhance tumor-centered distribution of nanoparticles because of enhanced permeability and retention effect but also promote more lymphocytes to migrate into tumor tissues for eradication of tumor. The physical and chemical features of the nanoparticles and the stimulation of lymphocytes by nanoparticle-transfected cells both in vitro and in vivo were evaluated. The distribution and antitumor effect of the dsNKG2D-IL-21 gene nanoparticles in mice were also assessed.

\section{Materials and methods}

\section{Plasmids, reagents, antibodies, and cell lines}

The recombinant pcDNA3.1(-)-dsNKG2D-IL-21 plasmid was previously generated in our laboratory in accordance with standard methods. ${ }^{10}$ The gene fragment of $\beta 2$-microglobulin signal peptides was also added upstream the NKG2D gene. Liposome (Lipofectamine ${ }^{\mathrm{TM}}$ 2000) was obtained from Invitrogen (Grand Island, NY, USA). EndoFree Plasmid Maxi Kit from Qiagen (Düsseldorf, Germany) was further used to deplete endotoxin. Chitosan (MW $20 \mathrm{kDa}$ ) with 75\% to $85 \%$ deacetylation was purchased from Yuhuan County Marine Chemical Company (Yuhuan, Zhejiang, China). Antibodies against CD4 (GK1.5), CD8 (53.67), CD49b (DX5), CD69 (LG.3A10), CD107a (1D4B), and CD44 (IM7) were all purchased from Biolegend (San Diego, CA, USA). Recombinant IL-21 and murine NKG2D-Ig proteins were from R\&D systems (Minneapolis, MN, USA). YAC-1,
NIH-3T3, CT-26, and RAW264.7 cell lines were obtained from ATCC.

\section{Preparation of chitosan-plasmid nanoparticles}

The pcDNA3.1-dsNKG2D-IL-21 plasmids were isolated and purified by the use of plasmid extraction columns. Chitosan was chemically modified with $N$-(2-hydroxyl) propyl-3-trimethyl ammonium by the redox polymerization technique as described by $\mathrm{Hu}$ et al. ${ }^{11}$ The plasmids and chitosan were, respectively, dissolved in ultrapure water to obtain $1 \mu \mathrm{g} / \mu \mathrm{L}$ solutions. The plasmid solution was mixed with chitosan solutions at a mass ratio of $1: 2,1: 1$, or $2: 1$. The mixed solutions were fully vibrated and centrifuged to form precipitation. Nanoparticles in sediments were dissolved in phosphate-buffered saline for further analysis. ${ }^{12}$

\section{Physicochemical characterization of chitosan-plasmid nanoparticles}

The encapsulation rate of nanoparticles was calculated by the plasmid amount in the nanoparticle proportion to the total amount. Free plasmids in the supernatants were detected by ultraviolet spectrophotometer and confirmed by electrophoresis. Aqueous solutions of the chitosan/DNA complexes were analyzed by dynamic light scattering and zeta potential measurements (Zetasizer Nano ZS 90; Malvern, Worcestershire, UK) to determine their particle size and zeta potential. The sizes of the nanoparticles were confirmed under an electron microscope (Tecnai 12; Philips, Amsterdam, the Netherlands).

\section{Identification of dsNKG2D-IL-2 I secretion by cells}

Murine colon epithelial carcinoma CT-26 cells or murine fibroblast NIH-3T3 cells in log phase were plated onto a 24-well plate. Chitosan-plasmid nanoparticle (10\% or $20 \%$ dilution in Dulbecco's Modified Eagle's Medium) was added into plates. No-load chitosan nanoparticles served as negative control. DsNKG2D-IL-21 secretion in cell supernatants was assessed after $48 \mathrm{~h}$ using an enzyme-linked immunosorbent assay (ELISA) kit from R\&D Systems (Boston, MA, USA).

\section{Western blot}

The supernatants of transfected cells were separated by polyacrylamide gel electrophoresis and then transferred to polyvinylidene fluoride (PVDF) membranes. After blocking with $5 \%(w / v)$ nonfat dry milk powder in Tris Buffered Saline with tween-20, the membrane was incubated with anti-NKG2D 
pAb (Ab96606, Abcam, Cambridge, UK) or anti-IL-21 pAb (Ab5978, Abcam) in 1:500 dilutions for $2 \mathrm{~h}$ at $37^{\circ} \mathrm{C}$. The PVDF membranes were then incubated with goat anti-rabbit immunoglobulin $\mathrm{G}$ (1/3,000 in TBST) (Invitrogen) conjugated with horseradish peroxidase for $1 \mathrm{~h}$. Finally, the immunoreactive bands on membranes were read by a chemiluminescence reagent (Dakewei, Shenzhen, China).

\section{Viability of cells transfected with dsNKG2D-IL-2I nanoparticles}

After CT-26, NIH-3T3, and RAW264.7 cells $\left(5 \times 10^{3}\right)$ were transfected by the chitosan-plasmid nanoparticles, an MTS/PMS kit from Promega (Madison, WI, USA) was used to check the viability. Cell wells were added with various doses of no-load chitosan particles $(1.25,2.5$, and $5 \mu \mathrm{g})$ and chitosan-plasmid particles $(1.25,2.5$, and $5 \mu \mathrm{g})$ for $24 \mathrm{~h}$. Each well was then added with the 3-(4,5dimethylthiazol-2-yl)-5-(3-carboxymethoxyphenyl)-2-(4sulfophenyl)-2H-tetrazolium/phenazine methosulfate (MTS/ PMS) solution. After incubation for $4 \mathrm{~h}$, the absorption of each well at $490 \mathrm{~nm}$ was detected to evaluate live cells. The cytotoxicity of nanoparticles on different cell lines was calculated by using the rate of inhibition under various quantities of nanoparticles. Half-maximal inhibitory concentration $\left(\mathrm{IC}_{50}\right)$ was also deduced.

\section{Stimulation of lymphocytes in vivo}

Chitosan-plasmid nanoparticles at a dose of 50 or $100 \mu \mathrm{g}$ were injected into the muscles of back legs of normal mice (Balb/c) daily for 3 days. Similar amounts of pure plasmids $(100 \mu \mathrm{g})$ and no-load nanoparticles were used as negative controls. On day 4, all mice were killed. Sera and spleens were isolated and collected. Serum IL-21 levels were examined by the ELISA kit from R\&D Systems (Boston, MA, USA) as previously described. Splenic mononuclear cells were used to further analyze CD69 or $\mathrm{CD} 44$ expression by $\mathrm{CD}^{+}, \mathrm{CD}^{+}$, or $\mathrm{NK}$ cells. The cytotoxicity of NK cells was assessed based on the CD107a expression detected by flow cytometry.

\section{Detection of NK cell degranulation}

The activity of NK cell degranulation reflects its cytotoxicity. In brief, anti-CD107a monoclonal antibody ( $\mathrm{mAb}$ ) or isotype control antibody was added into the culture system, when effectors were mixed with YAC-1 target cells with a 3:1 ratio. After $2 \mathrm{~h}$ of coincubation, monensin $(10 \mu \mathrm{m})$ (GolgiStop; BD Biosciences, San Jose, CA, USA) was added for another $2 \mathrm{~h}$. Then, cells were collected and stained with DX5 mAb (an NK cell marker) for 30 min on ice and analyzed by flow cytometry.

\section{In vivo nanoparticle distribution}

Chitosan was conjugated with cyanine dye 5.5 (purity: 95\%) by Shanghai Kaiji Biotechnology (Shanghai, China). Fluorescent chitosan was employed to generate dsNKG2DIL-21 gene nanoparticles as performed previously. The back of Balb/c mice $(n=3)$ was subcutaneously transplanted with CT-26 cells $\left(5 \times 10^{6}\right)$. Fluorescent nanoparticles $(50 \mu \mathrm{g})$ were injected into the tail vein of mice on day 10 . In vivo fluorescent signals were captured at $0.5,1,2,4,8,20$, and $24 \mathrm{~h}$ by a Shimadzu OPTplus imaging system.

\section{Mouse tumor models}

Balb/c mice were subcutaneously injected with CT-26 cells $\left(n=6 ; 2 \times 10^{6}\right.$ cells) into the back. Since day 5 , the mice were treated with chitosan-dsNKG2D-IL-21 gene nanoparticles $(50$ or $100 \mu \mathrm{g}$ ) through intramuscular injection every 3 days. The commercial recombinant murine IL-21 protein $(60 \mu \mathrm{g})$ was used in parallel as positive control. Tumor growth was checked with digital calipers daily, and tumor volume was calculated as $\mathrm{V}=(\text { width })^{2} \times$ length $/ 2$. All mice were killed on day 21, and their spleens were collected. Mononuclear cells of spleens were isolated, and CD69 or CD44 expression in $\mathrm{CD}^{+}, \mathrm{CD}^{+}$, or $\mathrm{DX}^{+}$cell was analyzed by flow cytometry. Mouse viability was documented daily. All experiments were conducted in accordance with the protocols approved by the Yangzhou University's Institutional Animal Care and Use Committee. Yangzhou University's Institutional Animal Care and Use Committee approved this research.

\section{Isolation of lymphocytes from tumor tissues}

Tumor tissues from mice were finely cut and ground. Digestive solutions with collagenase type III $(100 \mathrm{mg} / \mathrm{mL})$, dispase $(550 \mathrm{mg} / \mathrm{mL})$, and DNase I $(300 \mathrm{mg} / \mathrm{mL})$ were added to tissues for 4-6 h. Cell suspensions were sequentially sieved through 70 and $40 \mu \mathrm{m}$ pore strainers and treated with Tris$\mathrm{NH}_{4} \mathrm{Cl}$ lysis buffer for eradication of red blood cells. After being isolated by centrifugation in 35\% Percoll, lymphocytes were incubated with $\mathrm{mAb}$ against DX5 and CD69, CD44, or CD107a and detected by flow cytometry.

\section{Statistics}

Differences between two groups were analyzed by Student's $t$-test. Analysis of variance was used, when the number of treatment groups was more than two. Survival curves were plotted by Kaplan-Meier analysis. All analyses were conducted with the GraphPad Prism software. $P<0.05$ was considered statistically significant. 


\section{Results}

Preparation of nanoparticles loaded with the dsNKG2D-IL-2I fused gene

We assessed the plasmid encapsulation rates by chitosan nanoparticles initially generated at different weight ratios. No excess DNA appeared in the supernatants when chitosan was mixed with plasmid at a mass ratio of $2: 1$ or $1: 1$ (Figure 1A); some free DNA was observed in the ratio of $1: 2$. The mean encapsulation rate reached $92.8 \% \pm 2.0 \%$ or $93.9 \% \pm 1.7 \%$ in the ratio of $2: 1$ or $1: 1$ (Figure $1 \mathrm{~B}$ ). The size and morphology of the nanoparticles were detected under electronic microscope. The particle sizes were even

A

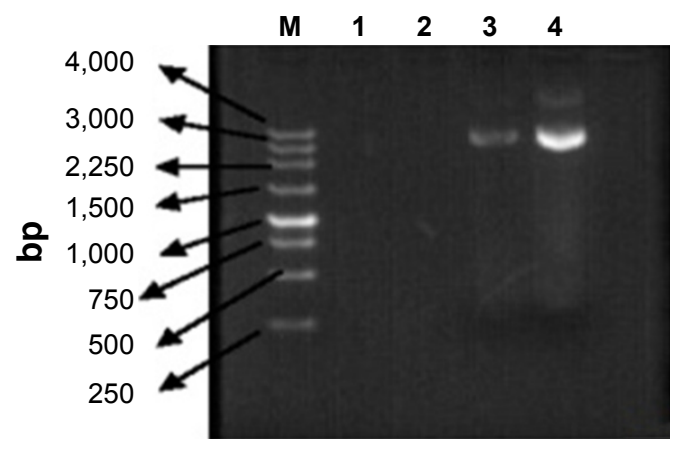

M: DNA ladder

1: Chitosan:plasmid $=2: 1$

2: Chitosan:plasmid $=1: 1$

3: Chitosan:plasmid $=1: 2$

4: Plasmid of pcDNA3.1-dsNKG2D-IL-21

B

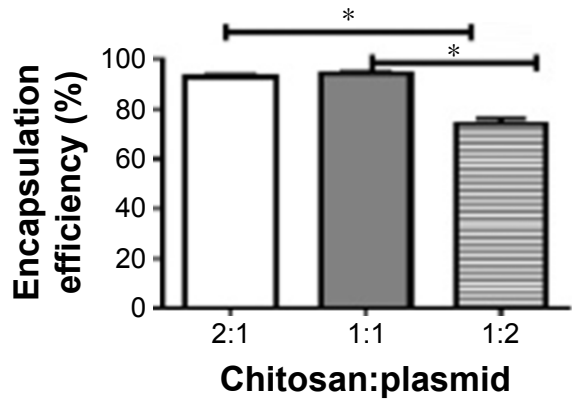

C

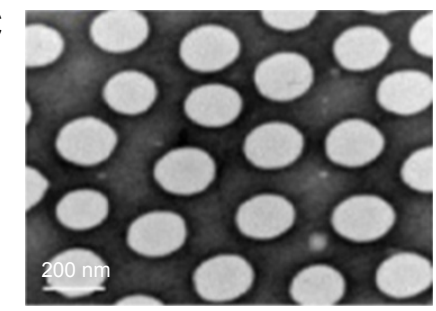

Chitosan:plasmid

D

Size distribution by intensity

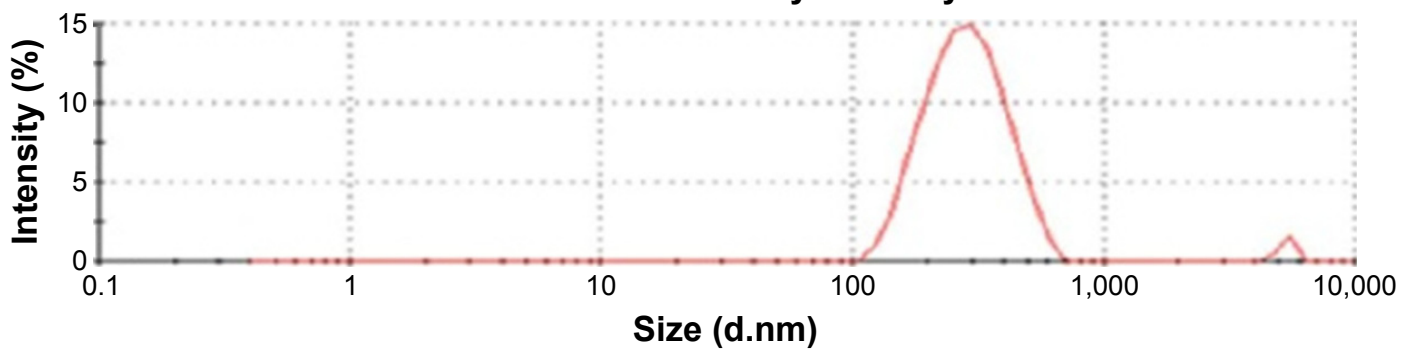

E

Zeta potential distribution

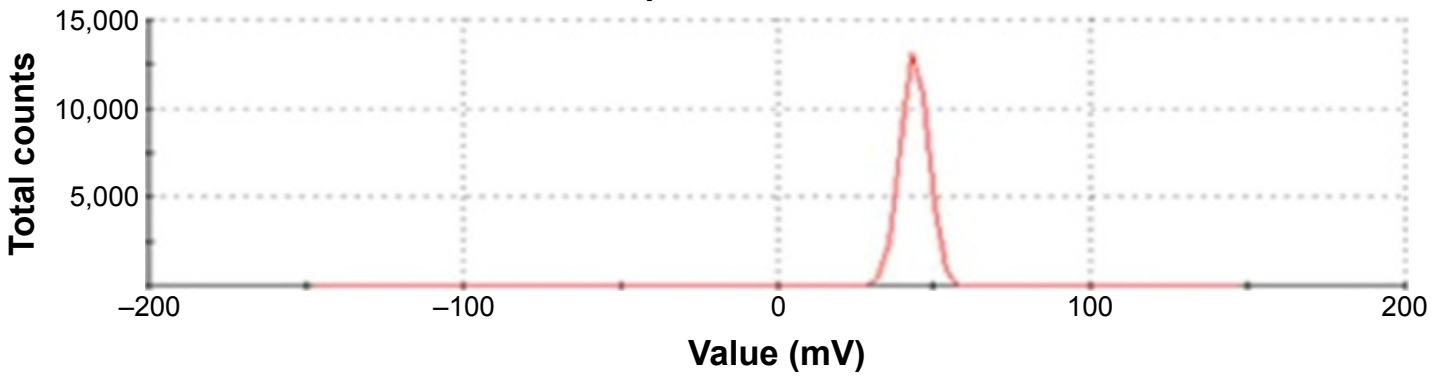

Figure I Generation and identification of chitosan nanoparticles encapsulated with the dsNKG2D-IL-2I fusion gene.

Notes: Agarose gel electrophoresis of supernatant solutions after nanoparticles were centrifuged with different ratios of chitosan to pcDNA3.I (weight:weight) (A). Encapsulation rate was calculated by the ratio of the amount of DNA encapsulated into the nanoparticles to the total DNA quantities (B). Transmission electron microscopy displayed the morphology and size of nanoparticle (C). Size (D) and zeta-potential distribution (E). Each experiment was repeated at least three times. $* P<0.05$. Abbreviation: IL-2I, interleukin 2I. 
with diameters of $\sim 200 \mathrm{~nm}$ (Figure 1C). Diameters of nanoparticles distributed from 200 to $400 \mathrm{~nm}$ (Figure 1D) as confirmed by a dynamic light scattering apparatus, and zeta potential of the nanoparticles exhibited a mean value of $42.0 \pm 0.56 \mathrm{mV}$ (Figure 1E).

\section{DsNKG2D-IL-2I secretion by nanoparticle-transfected cells}

DsNKG2D-IL-21 production by CT-26 cells, which were previously transfected with pcDNA3.1-dsNKG2D-IL-21 through liposome, has been previously identified through detection of both NKG2D by flow cytometry-intracellular staining and IL-21 in cell supernatants by ELISA. ${ }^{10}$ After CT-26 or NIH-3T3 cells were transfected with $20 \%$ dsNKG2D-IL-21 nanoparticles, ELISA results showed that the IL-21 concentrations of both cell supernatants were significantly enhanced relative to that of the no-load nanoparticles (Figure 2A and B). In addition, Western blot results showed that the cell supernatants were clearly stained by either NKG2D antibody or IL-21 antibody (Figure 2C). Therefore, the dsNKG2D-IL-21 protein could be secreted by epithelial cells or fibroblasts that are pretransfected by the dsNKG2D-IL-21 chitosan-plasmid nanoparticles.

\section{Enhancement of lymphocyte activation by nanoparticle-transfected cells}

After the dsNKG2D-IL-21 nanoparticle-transfected CT-26 cells were cocultured with mononuclear cells of spleens overnight, CD69 of NK cells or CD44 of CD8 ${ }^{+}$cells was detected. Liposome-mediated transfection of the dsNKG2D-IL-21 plasmid and the commercial recombinant IL-21 protein were used as positive controls. As expected, the expression level of CD69 in NK cells significantly increased after coculture with 20\% dsNKG2D-IL-21 nanoparticle-transfected CT-26 cells (Figure 3A). Similarly, the CD44 expression of CD8 ${ }^{+}$ cells was enhanced by $20 \%$ dsNKG2D-IL-21 nanoparticle treatment (Figure 3B). Subsequently, cytotoxicity values of nanoparticles in CT-26, NIH-3T3, or RAW264.7 cell were detected by MTS/PMS method. The linear relationship between nanoparticle quantity and inhibition rate and $\mathrm{IC}_{50}$ of nanoparticles of each cell type is shown in Figure 3C. No significant chitosan nanoparticle cytotoxicity was noted

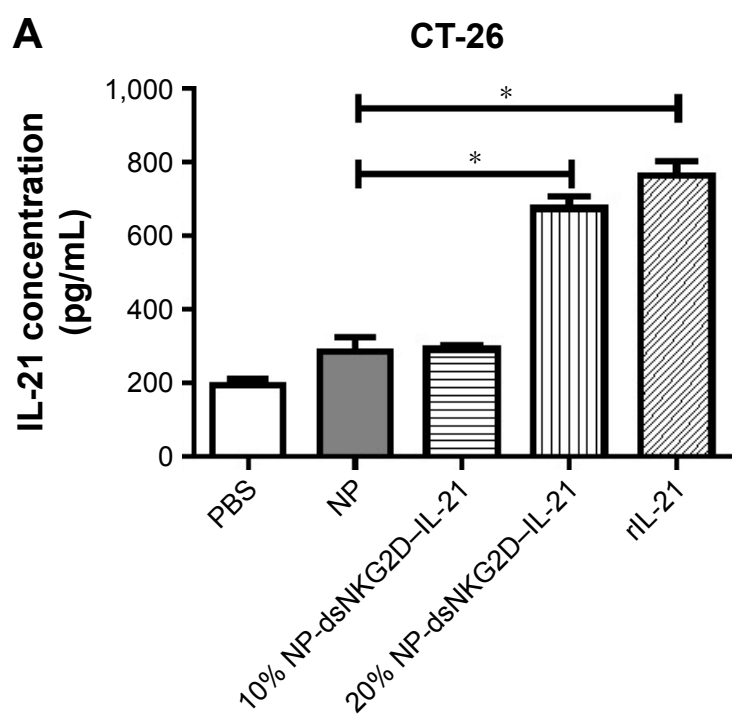

B NIH-3T3

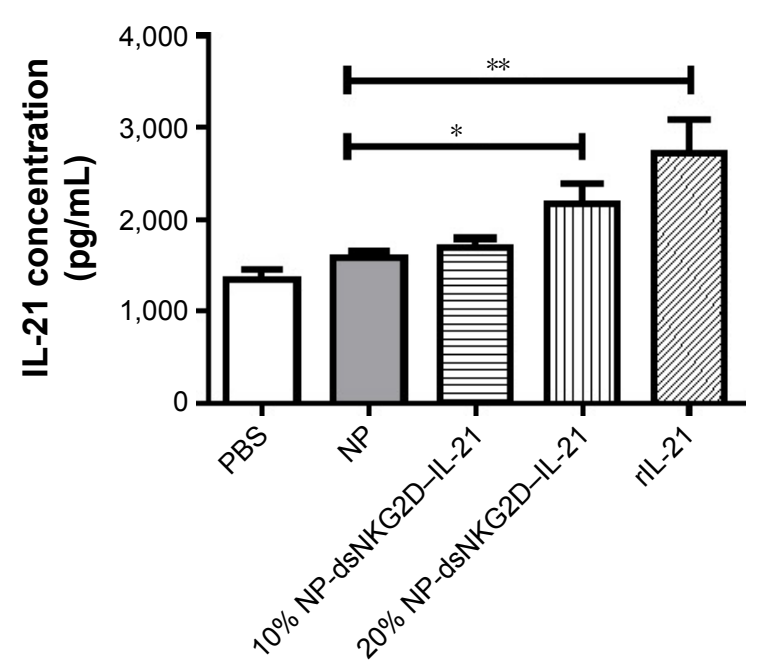

C $20 \% \mathrm{NP}$ -

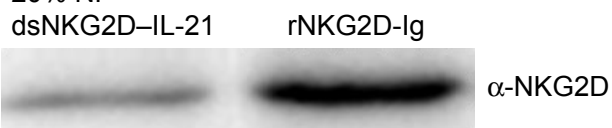

$20 \%$ NP-

dsNKG2D-IL-21

rIL-21

$\alpha-I L-21$

Figure 2 Identification of the secreted dsNKG2D-IL-2 I protein.

Notes: Supernatants of CT-26 (A) or NIH-3T3 cell (B) pretransfected with $10 \%$ or $20 \%$ chitosan-dsNKG2D-IL-2I gene nanoparticles were collected to determine dsNKG2D-IL-2I concentration by ELISA. The NKG2D-IL-2I fusion protein of cell supernatants was confirmed by Western blot (C). Each experiment was conducted three times. $* P<0.05$, $* * P<0.01$.

Abbreviations: ELISA, enzyme-linked immunosorbent assay; IL-2I, interleukin 2I; NP, nanoparticle; PBS, phosphate-buffered saline. 
at the dose 1.25 or $2.5 \mu \mathrm{g}$, but the $5.0 \mu \mathrm{g}$ dose exerted toxic effects on the three cell types (Figure 3D).

\section{Simulation of lymphocytes by the}

\section{dsNKG2D-IL-2I nanoparticles in vivo}

Normal mice were injected intramuscularly with chitosandsNKG2D-IL-21 nanoparticles daily for 3 days. Serum IL-21 levels of mice were significantly enhanced after treatment with dsNKG2D-IL-21 nanoparticles at doses of 50 and $100 \mu \mathrm{g}$ compared with no-load nanoparticles (Figure 4A). Higher frequencies of splenic $\mathrm{CD} 4^{+} \mathrm{CD} 69^{+}$and $\mathrm{CD} 4^{+} \mathrm{CD} 44^{+}$ cells (Figure 4B), as well as $\mathrm{CD} 8^{+} \mathrm{CD} 69^{+}$and $\mathrm{CD} 8^{+} \mathrm{CD} 44^{+}$ cells (Figure $4 \mathrm{C}$ ), were found in the mice treated with dsNKG2D-IL-21 nanoparticles. NK cell is the first defense line against tumor. Treatment with dsNKG2D-IL-21 nanoparticles at both doses significantly enhanced the frequencies

A
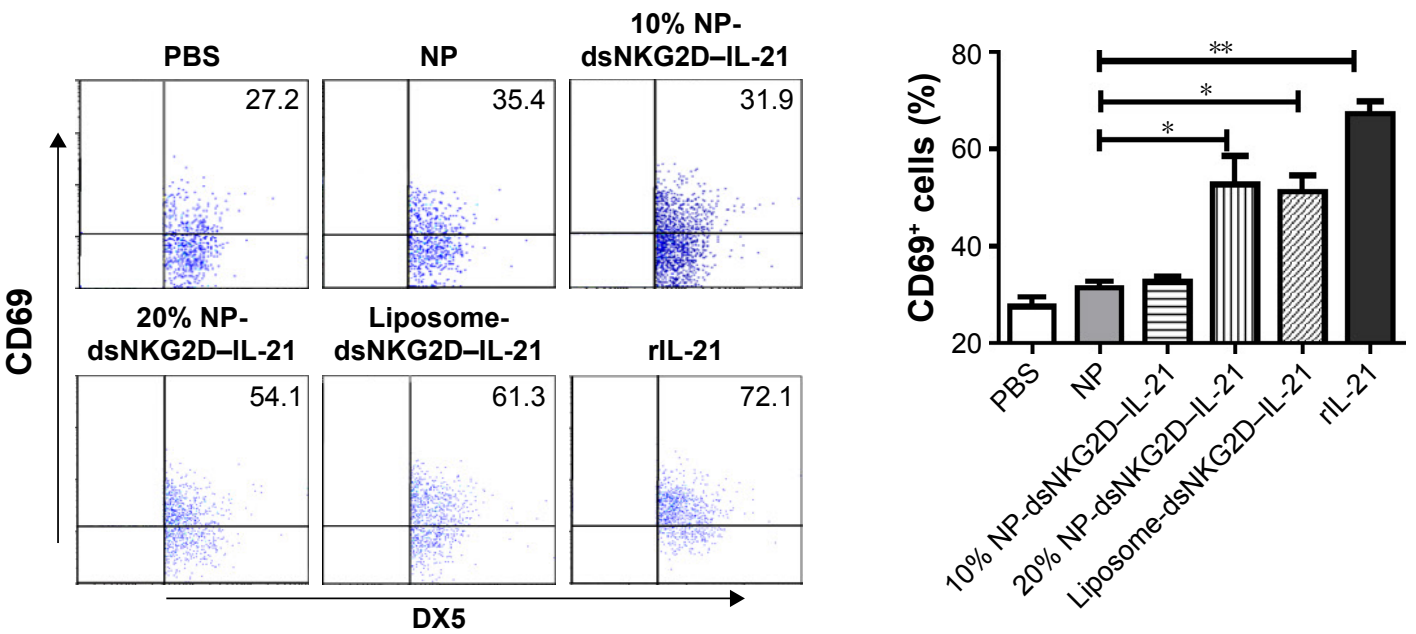

B
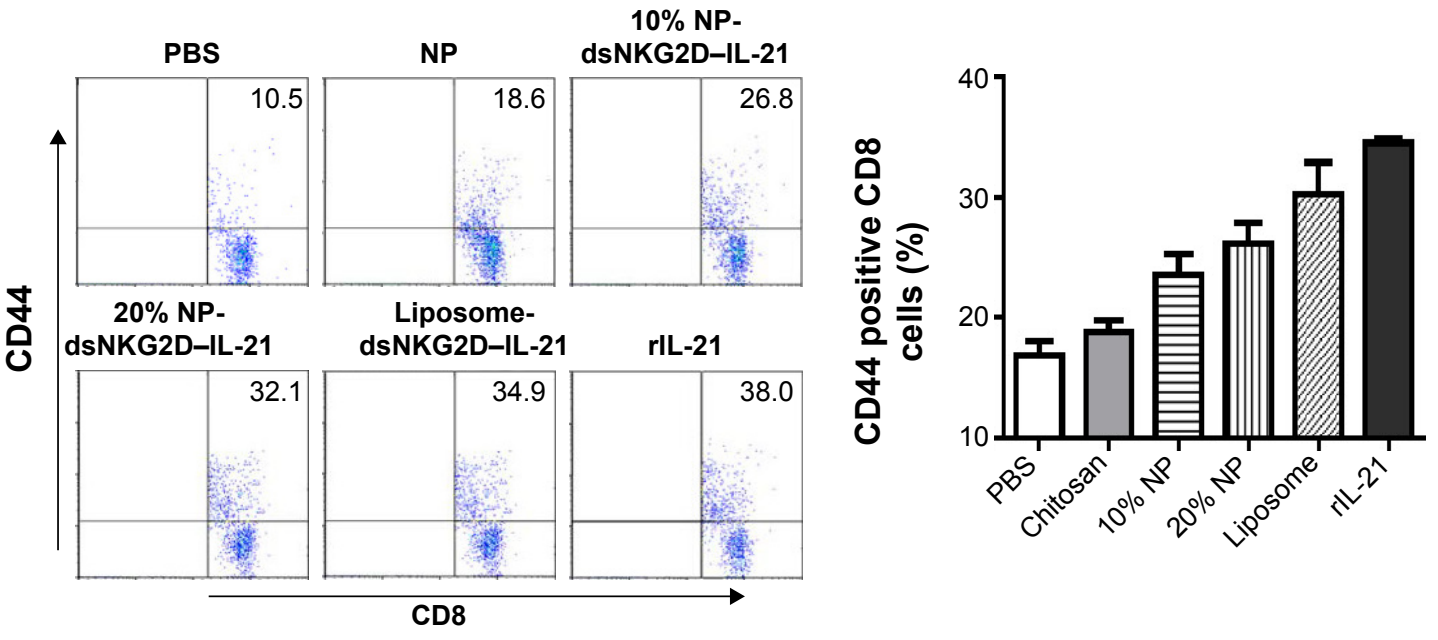

C

CT-26

NIH-3T3

RAW264.7
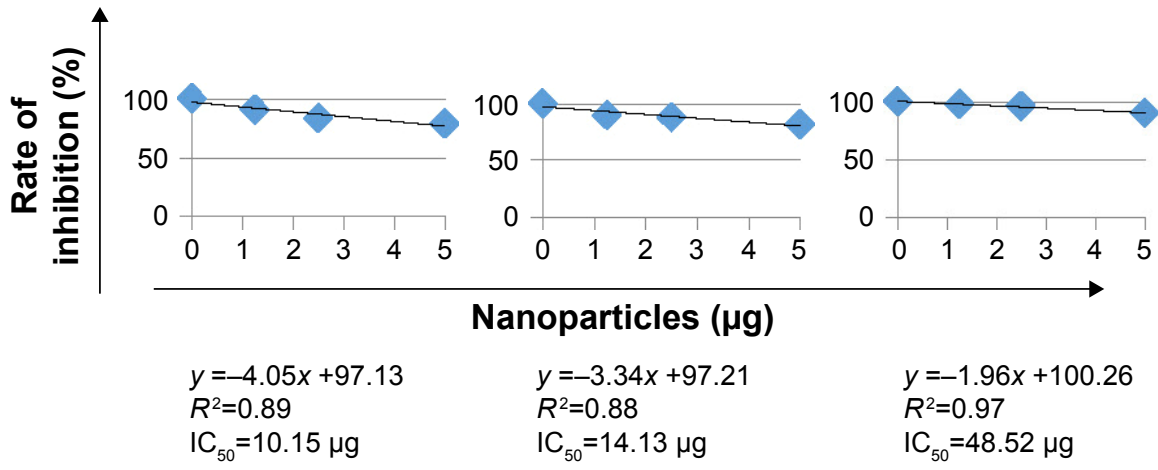

Nanoparticles $(\mu \mathrm{g})$

Figure 3 (Continued)

$y=-1.96 x+100.26$

$R^{2}=0.97$

$\mathrm{IC}_{50}=48.52 \mu \mathrm{g}$ 

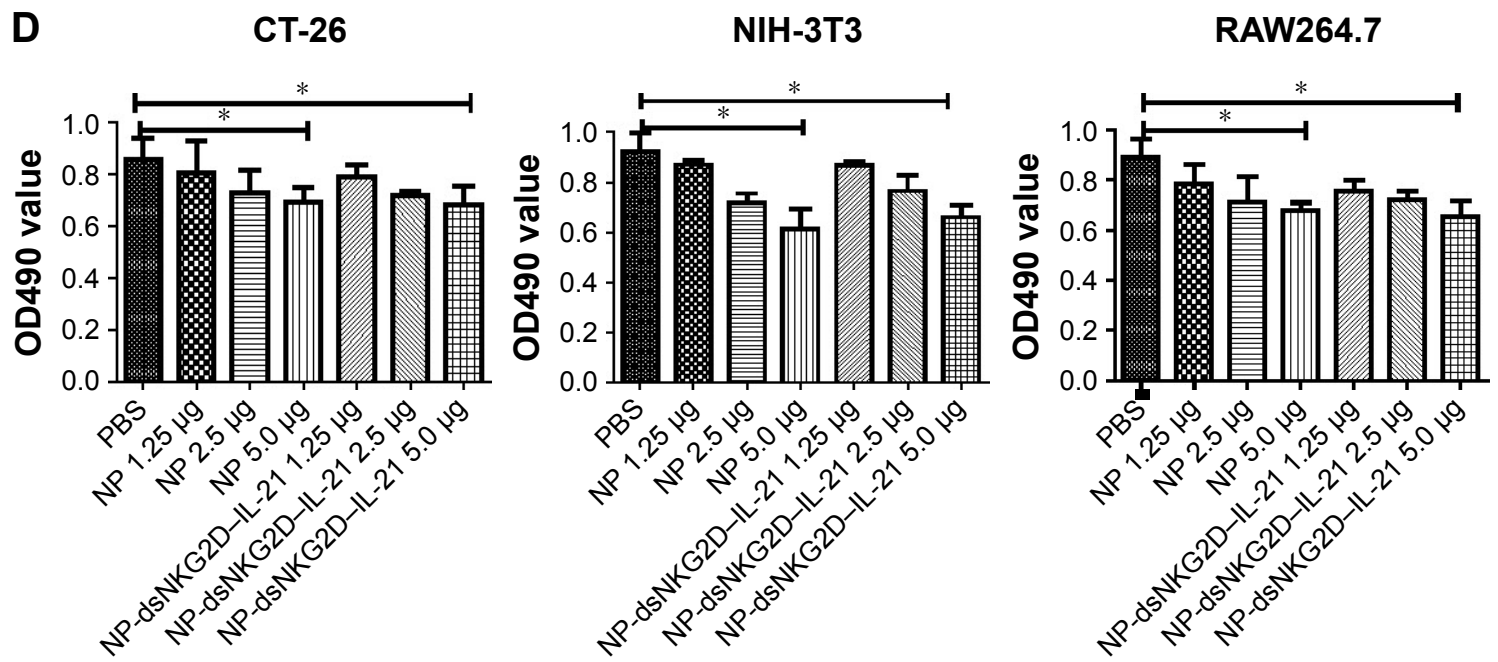

Figure 3 Stimulation of NK and CD8+ T cells by tumor cells pretransfected with chitosan-dsNKG2D-IL-I5 gene nanoparticles in vitro.

Notes: CT-26 cells pretransfected with $10 \%$ or $20 \%$ chitosan-plasmid nanoparticles were cultured with mouse splenocytes overnight. Frequencies of DX5 $5^{+}$CD6 $9^{+}$(A) and $\mathrm{CD}^{+} \mathrm{CD}^{+} 4^{+}$(B) cells were detected by flow cytometry. Variations in CT-26, NIH-3T3, or RAW264.7 cell number were checked by MTS/PMS kit after cell in coculture with chitosan-plasmid nanoparticles with different quantities for $72 \mathrm{~h}$. Linear relationship of nanoparticle quantity with inhibition rate of each cell type is shown (C). Numbers of cells treated by nanoparticles were assayed by the absorbance at OD490 nm (D). Each experiment was performed three times. $* P<0.05$, $* * P<0.01$.

Abbreviations: IC $\mathrm{C}_{50}$, half-maximal inhibitory concentration; IL-I5, interleukin I5; NK, natural killer; NP, nanoparticle; PBS, phosphate-buffered saline; OD, optical density.

of $\mathrm{DX} 5^{+} \mathrm{CD} 69^{+}, \mathrm{DX} 5^{+} \mathrm{CD} 44^{+}$, and $\mathrm{DX} 5^{+} \mathrm{CD} 107^{+}$cells in the spleens of mice (Figure 4D). These results indicate that dsNKG2D-IL-21 nanoparticles could efficiently promote lymphocyte activation in vivo.

\section{Distribution of dsNKG2D-IL-2I nanoparticles in tumor-bearing mice}

Dynamic distribution of the chitosan-dsNKG2D-IL-21 nanoparticles in tumor-bearing mice was determined by living imaging system. Chitosan preconjugated with Cy5.5 fluorescein was used to encapsulate the dsNKG2D-IL-21 plasmid. The fluorescent chitosan-dsNKG2D-IL-21 nanoparticles were injected intravenously into the mouse pretransplanted with tumors. Approximately $4-8 \mathrm{~h}$ later, fluorescent signals were clearly accumulated at the sites of tumor tissues, and the fluorescent signal could even be detected after $24 \mathrm{~h}$ (Figure 5A). Fluorescent intensity in the back of tumor-bearing mice was quantified under different time points. From 4 to 24 h, fluorescence intensity was all enhanced in the back of mice, compared with that in $0.5,1$, or $2 \mathrm{~h}$ (Figure 5B). We concluded that chitosan-dsNKG2DIL-21 nanoparticles could accumulate and remain in tumor tissues for a relatively long time in vivo.

\section{Suppression of tumor growth by the dsNKG2D-IL-2I nanoparticles}

We speculated whether chitosan-dsNKG2D-IL-21 nanoparticles mediate antitumor effects in mice. Tumor growth was sharply retarded in the mice injected with dsNKG2D-IL-21 nanoparticles at doses of 50 and $100 \mu \mathrm{g}$ relative to that in the mice treated with the same amount of no-load nanoparticles (Figure 6A and B). In addition, the life span of mice with tumors was prolonged after injection with dsNKG2DIL-21 nanoparticles (Figure 6C). No difference was noted between the treatments of 50 and $100 \mu \mathrm{g}$ dsNKG2D-IL-21 nanoparticles, which indicated that $50 \mu \mathrm{g}$ dsNKG2D-IL-21 nanoparticles could sufficiently induce immune-stimulatory effect in vivo.

Whether the dsNKG2D-IL-21 nanoparticles mediated antitumor activity through lymphocyte activation was then determined. The lymphocyte frequencies in both tumor tissues and lymphocyte activation markers were analyzed. Compared with the no-load nanoparticles or pure plasmid, the dsNKG2D-IL-21 nanoparticles significantly increased the $\mathrm{CD}^{+}, \mathrm{CD}^{+}$, or $\mathrm{DX}^{+}$cell frequencies in tumor tissues. DsNKG2D-IL-21 nanoparticles also enhanced the CD4 ${ }^{+}$ $\mathrm{CD}_{4} 4^{+}$and $\mathrm{CD} 8{ }^{+} \mathrm{CD} 44^{+}$cell frequencies, which indicated that these $\mathrm{T}$ cells were in the activated state. The frequencies of $\mathrm{DX}^{+} \mathrm{CD}^{+} 9^{+}, \mathrm{DX}^{+} \mathrm{CD}^{+} 4^{+}$, and $\mathrm{DX} 5^{+} \mathrm{CD} 107 \mathrm{a}^{+}$ cells of tumor tissues were higher in the dsNKG2D-IL-21 nanoparticle treatment group than in the no-load nanoparticle group (Figure 6D-F). This finding indicated that dsNKG2DIL-21 nanoparticles could stimulate NK- and T-cell activities to antagonize tumor growth.

\section{Discussion}

Il-21 has wide stimulatory effects on T, B, and NK lymphocytes, which suggests that IL-21 may possess antitumor 


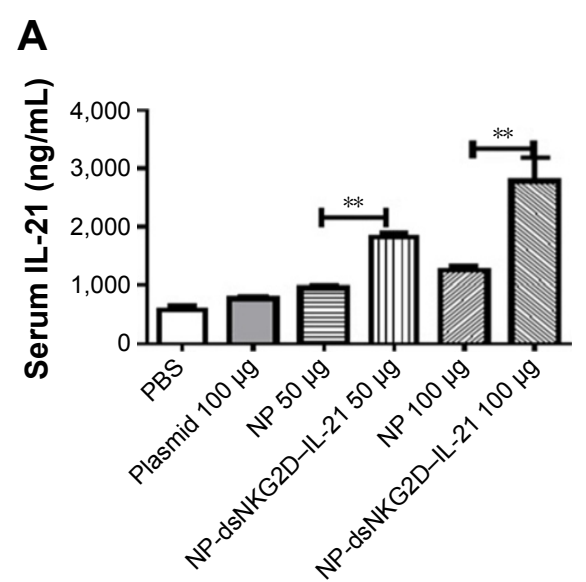

B $\quad \mathrm{CD}^{+} \mathrm{CD}^{+} 9^{+}$cells

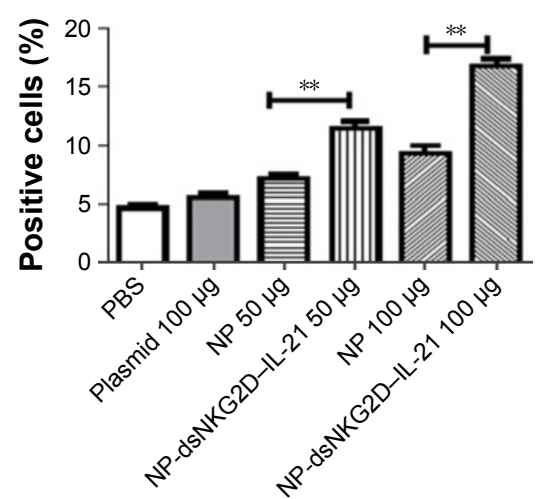

$\mathrm{CD}^{+}{ }^{+}$CD44 ${ }^{+}$cells

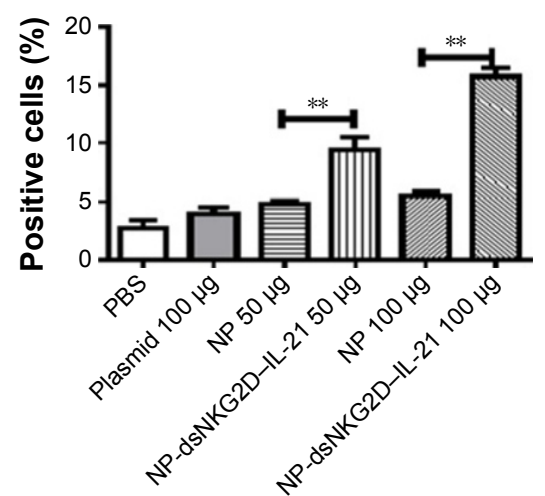

C

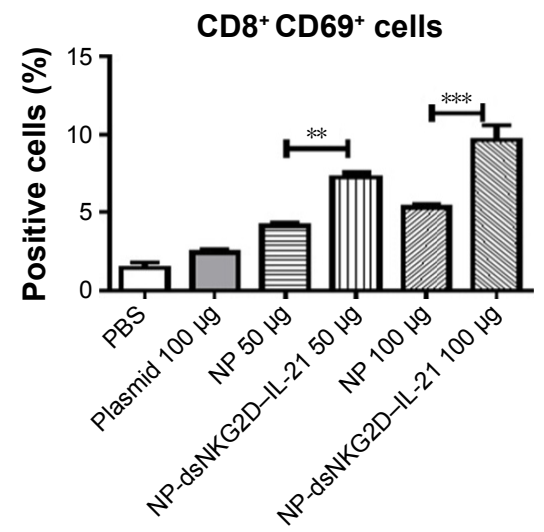

CD8 ${ }^{+}$CD44 ${ }^{+}$cells

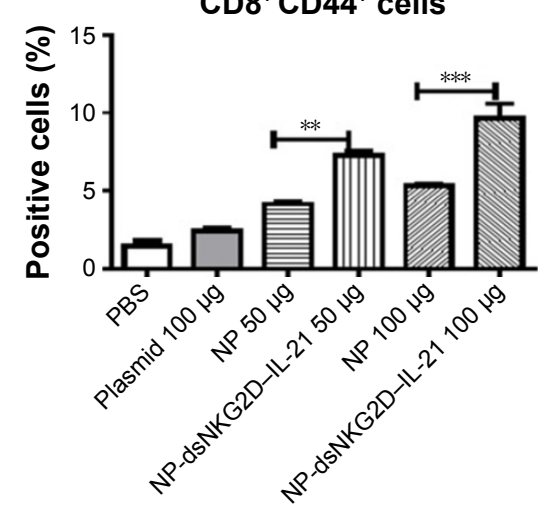

D

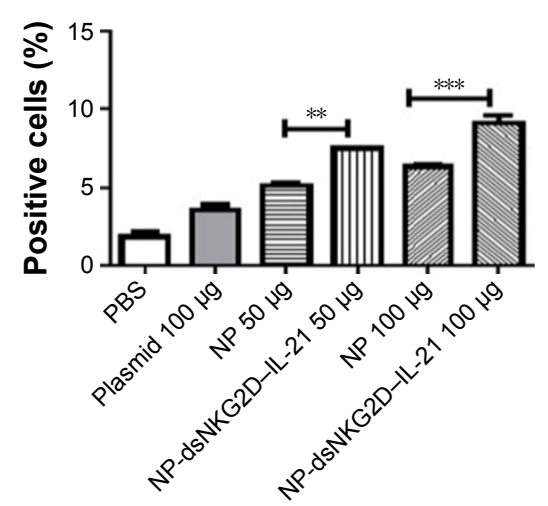

DX5 ${ }^{+}$CD $44^{+}$cells

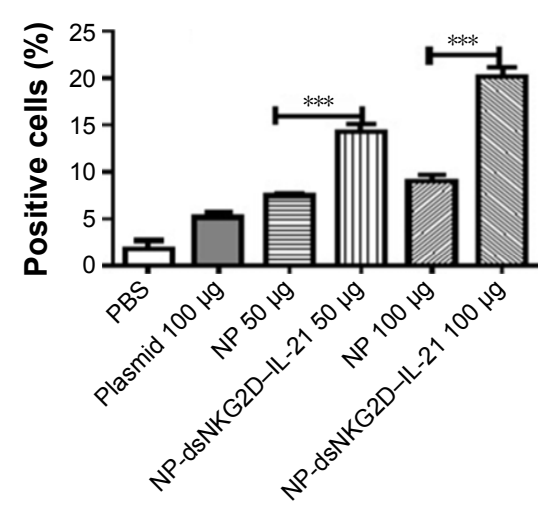

DX5 ${ }^{+}$CD107a ${ }^{+}$cells

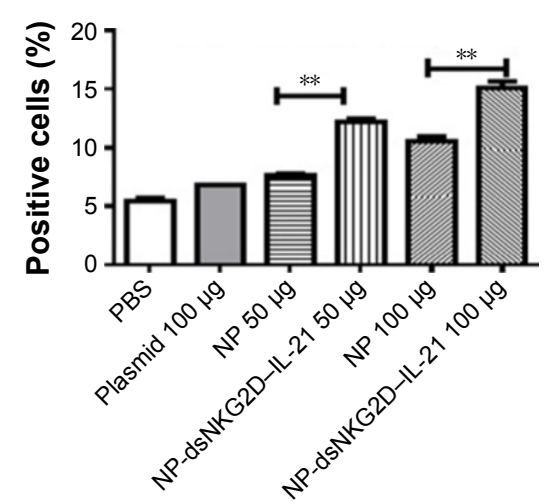

Figure 4 Activation of T and NK cells by the dsNKG2D-IL-2I nanoparticles in vivo.

Notes: Serum IL-2I levels of the mice injected with the nanoparticles intramuscularly for 3 days were detected by ELISA (A). CD69, CD44, or CDI07a expression level of splenic T or NK cells was detected by flow cytometry (B-D). Each experiment was performed three times. $* P<0.05, * * P<0.01, * * * P<0.00$ I.

Abbreviations: ELISA, enzyme-linked immunosorbent assay; IL-2I, interleukin 2I; NK, natural killer; NP, nanoparticle; PBS, phosphate-buffered saline.

activity. In the present study, the fused NKG2D and IL-21 gene fragment was delivered by chitosan-based nanoparticles. The size of DNA nanoparticles was even and showed diameters of $200-400 \mathrm{~nm}$ with positive charge. Cells could secrete the dsNKG2D-IL-21 protein after being transfected with chitosan nanoparticles. The secreted dsNKG2D-IL-21 protein stimulated $\mathrm{CD}^{+} \mathrm{T}, \mathrm{CD} 8^{+} \mathrm{T}$, and NK cell activation with low cytotoxicity on cells. After injection, the dsNKG2D-IL-21 nanoparticles preferentially accumulated in tumor tissues and suppressed tumor growth by activating $\mathrm{T}$ and NK cells in mice. Thus, dsNKG2D-IL-21 chitosan nanoparticles could be developed as a new reagent for tumor therapy.

Chitosan nanoparticles can automatically release drugs or genes in tumor tissues, due to hypoxia-induced acidic environment of tumors. ${ }^{9}$ The expression of genes delivered 

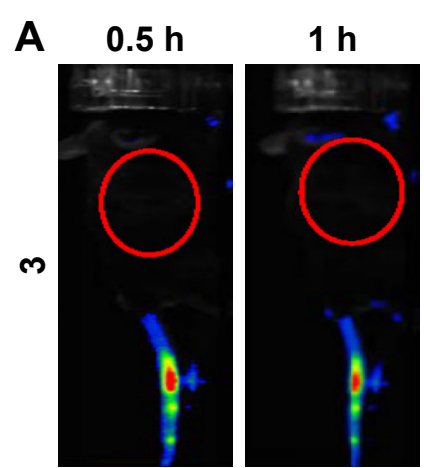

$2 \mathrm{~h}$
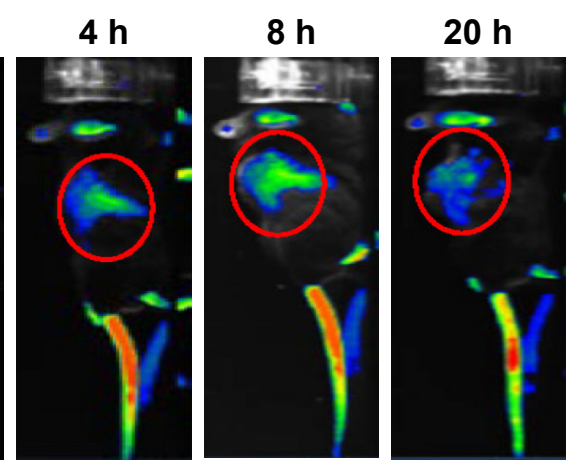

$24 \mathrm{~h}$
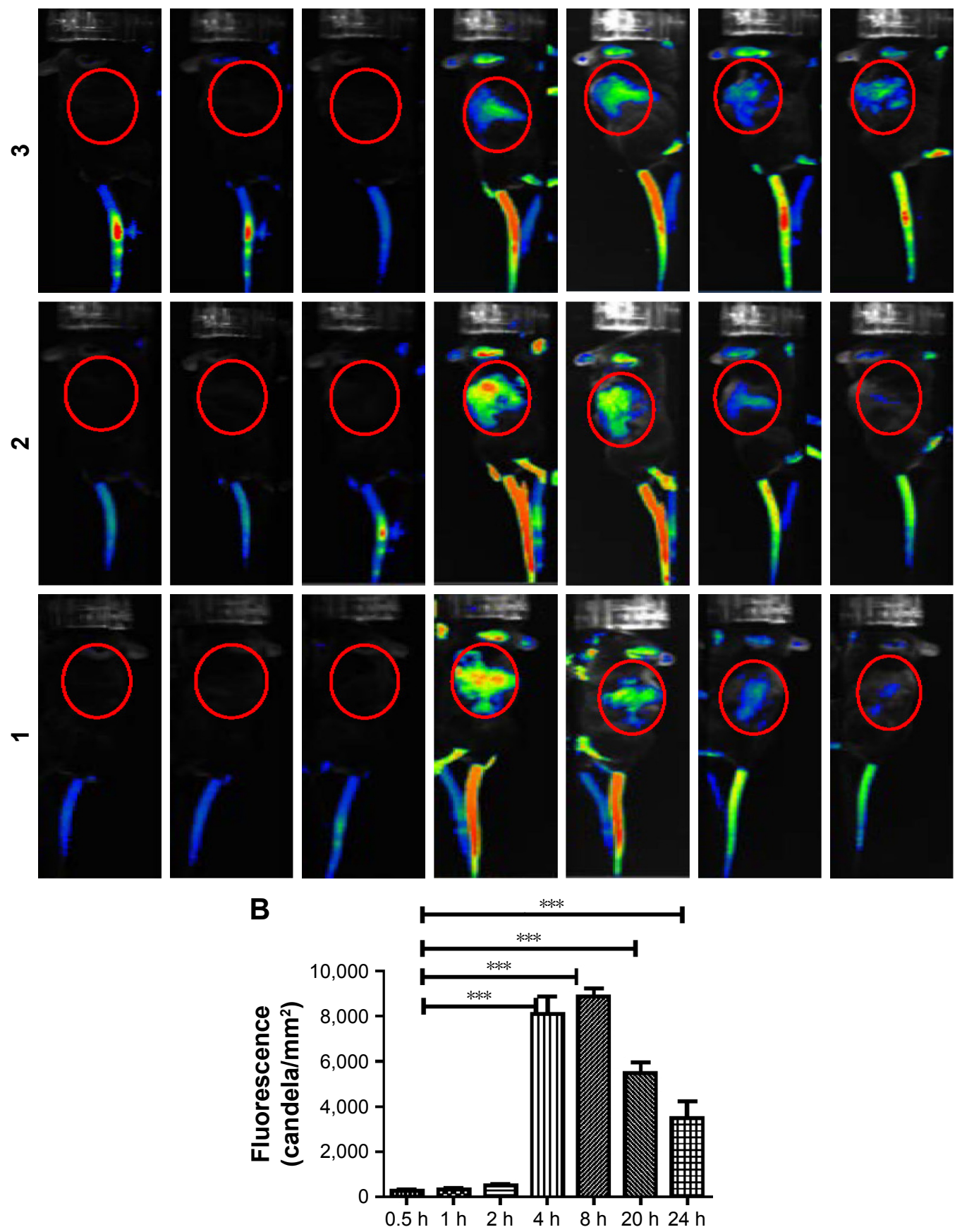

Figure 5 Distribution of dsNKG2D-IL-2I nanoparticles in tumor-bearing mice.

Notes: After CT-26 cells were subcutaneously injected into the back of C57BL6 mice for 10 days, Cy5.5-labeled chitosan-dsNKG2D-IL-2I (I00 $\mu$ g) nanoparticles were injected into the tail vein. Fluorescent signals in the three mice were documented as indicated (A). Fluorescent intensity of the red circle in the back of tumor-bearing mice $(\mathrm{n}=5)$ was compared $(\mathbf{B})$. The experiment was performed twice. $* * * P<0.001$.

Abbreviation: IL-2I, interleukin 2 I.

by nanoparticles would be a key factor for antitumor effects. The recombinant dsNKG2D-IL-21 protein could be detected in supernatants of transfected tumor cells and in sera of mice treated with dsNKG2D-IL-15 gene nanoparticles, which indicated that the chitosan nanoparticles were efficiently assimilated and expressed by cells in vitro or in vivo.
The antitumor activity by IL-21 strongly depends on its stimulation of NK and CD8 ${ }^{+}$T cells. ${ }^{13}$ If IL-21 plasmids are injected at the time of tumor cell inoculation, NK cells are activated to suppress lung and liver metastases. ${ }^{14,15}$ The IL-21 plasmids significantly possess antitumor effects on head and neck squamous cell carcinomas through activation of $\mathrm{T}$ and 
NK cells and generation of antibodies against tumor. ${ }^{16}$ The dsNKG2D-IL-21 nanoparticle-mediated activity against tumor tissues also involves $\mathrm{NK}$ and $\mathrm{CD}^{+} \mathrm{T}$-cell activation in the study. Although $\mathrm{CD}^{+} \mathrm{T}$ cells do not appear highly important in IL-21-mediated antitumor effects, ${ }^{17,18}$ the activation of total $\mathrm{CD}^{+}$cells was obvious in the present research. Variations in CD4+ $4^{+}$-cell subsets (Th1, Th2, Th17, or Treg) after treatment with the dsNKG2D-IL-21 gene nanoparticles still require further study.
In general, DNA vaccines may exert weaker effects than proteins expressed by the same gene. ${ }^{19}$ The antitumor effect mediated by the dsNKG2D-IL-21 gene nanoparticle was not better than that of recombinant IL-21, because using gene vaccines based on nanoparticles could be affected by phagocytosis of nanoparticles, efficient assimilation, and successive expression of the dsNKG2D-IL-21 gene by cells. However, the chitosan-nanoparticle-mediated delivery of the dsNKG2D-IL-21 gene fragment holds other advantages.
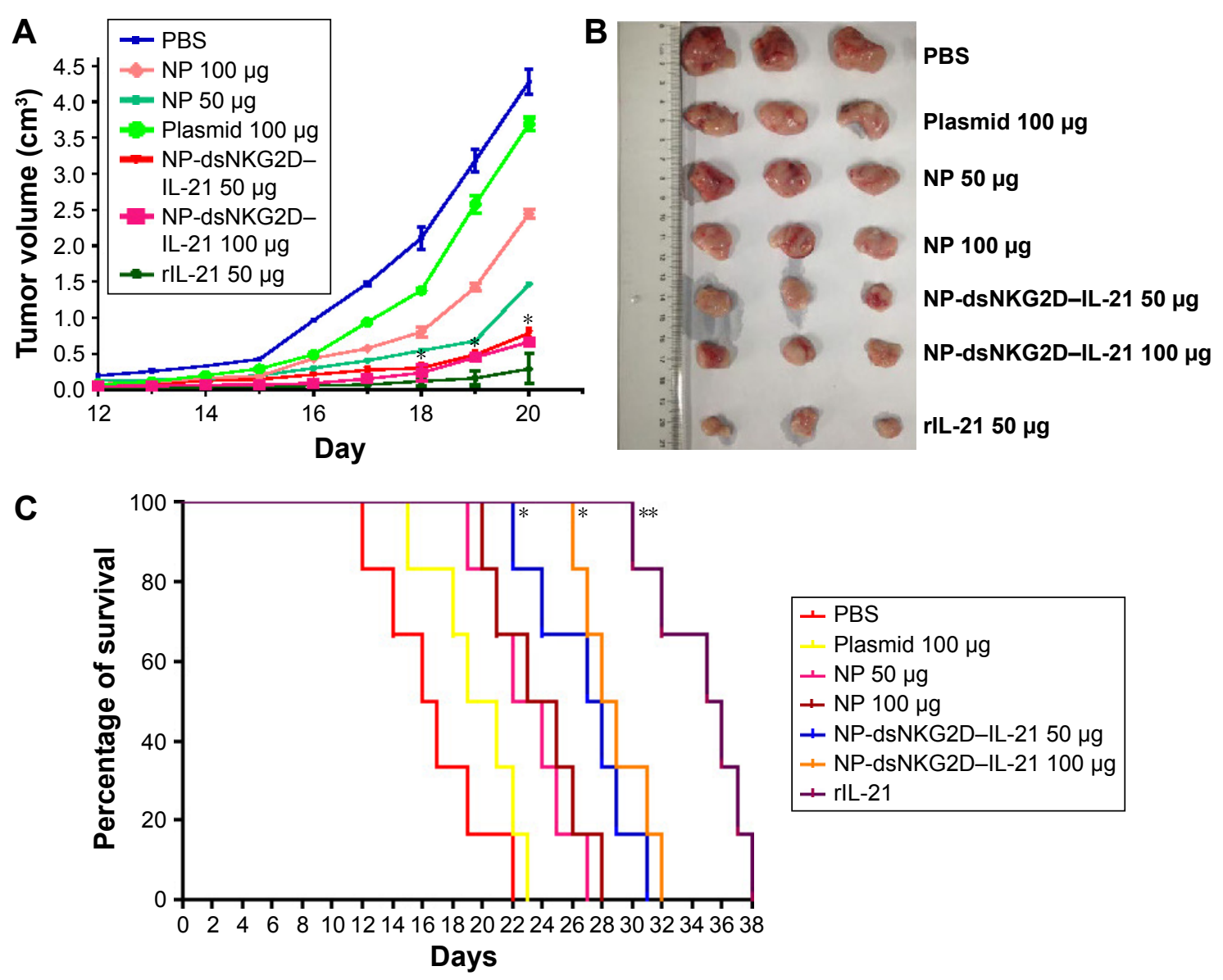

D

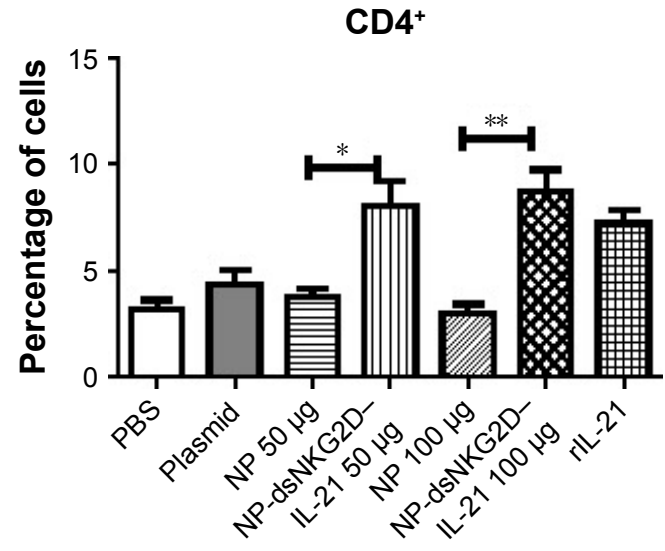

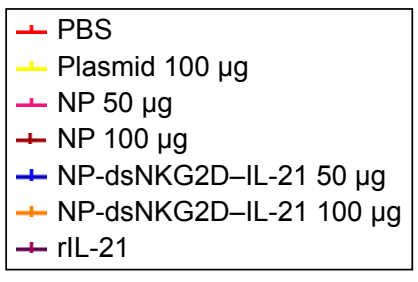

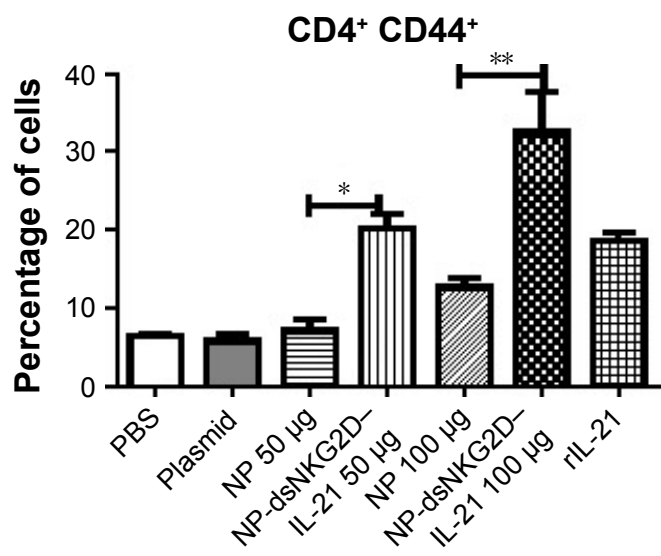

Figure 6 (Continued) 

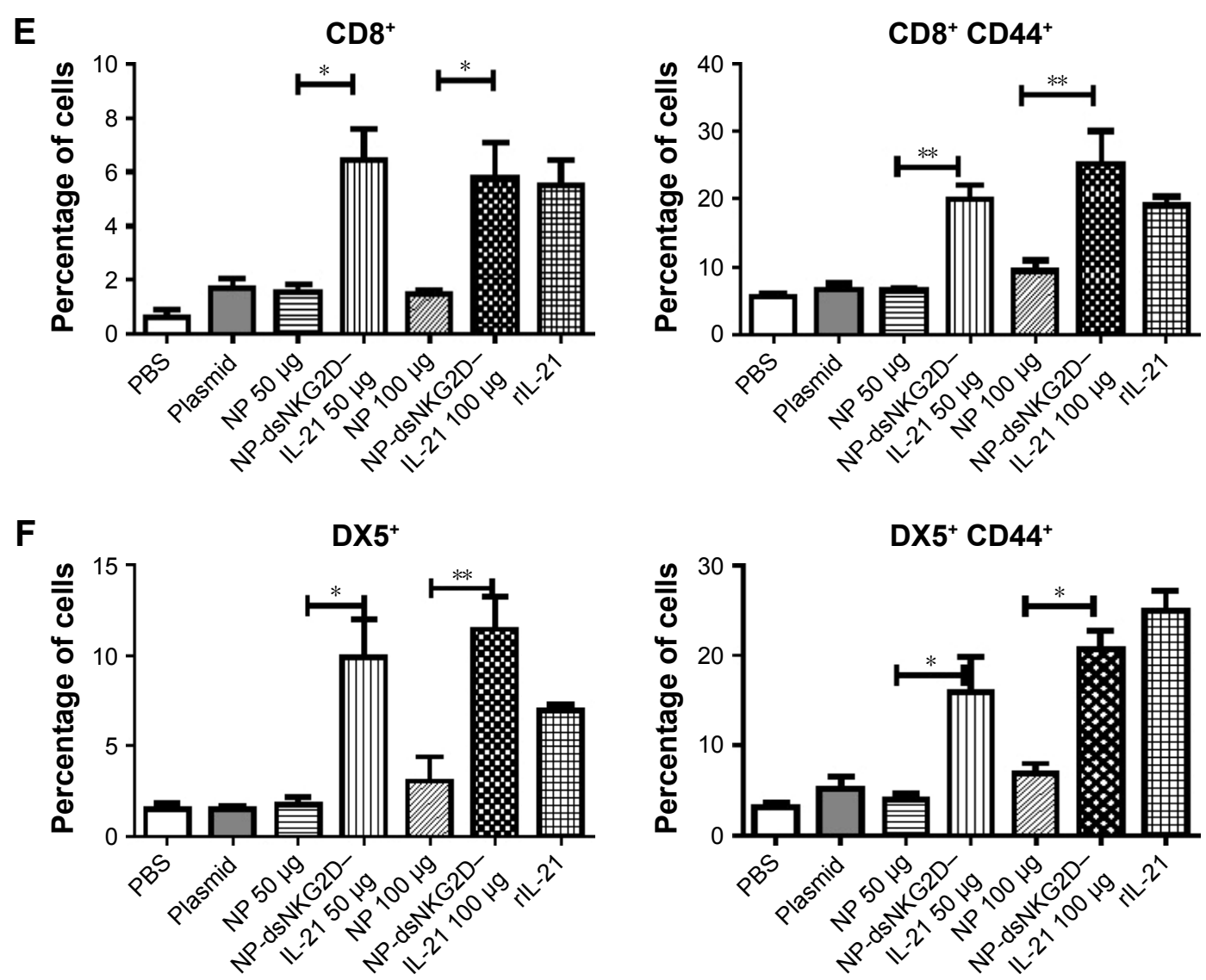

$\mathrm{DX5}^{+} \mathrm{CD}^{+} 9^{+}$
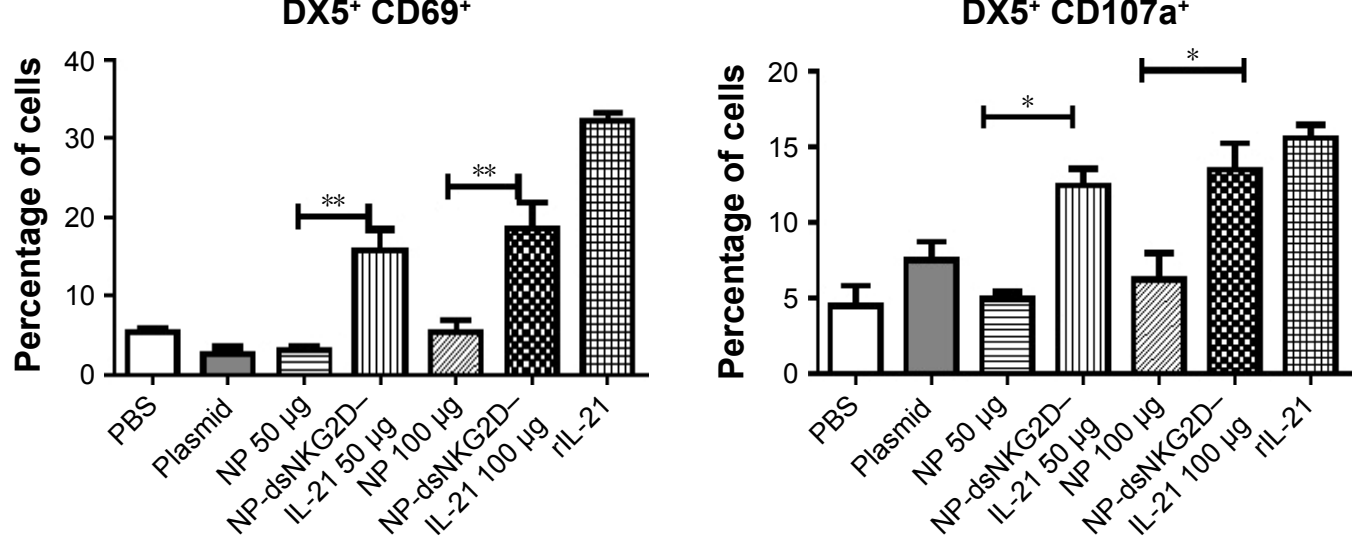

Figure 6 Antitumor activity of chitosan-dsNKG2D-IL-2I gene nanoparticles in vivo.

Notes: CT-26 cells were injected subcutaneously into the Balb/c mice ( $n=6,2 \times 10^{6}$ cells). On day 5 , nanoparticles were injected intramuscularly every 3 days. Tumor growth was measured daily and expressed as the mean \pm standard deviation (A). Tumor tissues were excised from the sacrificed mice (B). Mouse deaths were documented over time. Data are presented in Kaplan-Meier survival curves (C). All mice were sacrificed on day 20, and their spleens were collected. Frequencies of CD4+, CD4+ CD44+ (D), CD8 ${ }^{+}, \mathrm{CD}^{+} \mathrm{CD}^{4} 4^{+}(\mathrm{E}), \mathrm{DX} 5^{+}, \mathrm{DX} 5^{+} \mathrm{CD} 69^{+}, \mathrm{DX} 5^{+} \mathrm{CD} 44^{+}$, and $\mathrm{DX} 5^{+} \mathrm{CDI} 07 \mathrm{a}^{+}$cells in tumor tissues were detected by flow cytometry $(\mathbf{F})$. The experiment was conducted three times. $* P<0.05$, $* * P<0.01$.

Abbreviations: IL-2I, interleukin 2I; NP, nanoparticle; PBS, phosphate-buffered saline.

First, the enhanced permeation and retention ${ }^{20}$ effect of nanoparticles enabled the dsNKG2D-IL-21 nanoparticles to display tumor-centered distribution at $\sim 4-24 \mathrm{~h}$. Second, chitosan (a biological response modifier) synergizes with IL-21 to stimulate the immune system for tumor immune surveillance. ${ }^{21,22}$ Third, the expressed dsNKG2D-IL-21 protein was found with a larger molecular weight than the original protein, which indicates the long serum half-life of the fusion protein in vivo. ${ }^{23}$ Finally, compared with protein vaccines, the DNA vaccine was easier to manufacture and stock. ${ }^{24}$

A theoretical possibility is that NKG2D of NK and $\mathrm{CD} 8^{+}$ $\mathrm{T}$ cells can be competitively inhibited to ligate with RAE-1 
of tumor cells, if RAE- $1^{+}$tumor cells were prebound with the dsNKG2D-IL-21 protein. However, NK and CD8 ${ }^{+}$ $\mathrm{T}$ cells of tumor patients possessed lower NKG2D expression, particularly from patients at the late stage. Simultaneously, antitumor functions of $\mathrm{NK}$ and $\mathrm{CD} 8^{+} \mathrm{T}$ cells were significantly compromised. ${ }^{25,26}$ Thus, the competition event may seldom occur. The exogenous dsNKG2D-IL-21 protein would not suppress NK and $\mathrm{CD} 8^{+} \mathrm{T}$-cell functions but promote their stimulations through IL-21. In addition, another fusion protein, scFv-NKG2D, in which NKG2D is fused to an anti-CD3 single-chain variable fragment, is generated to engage both $\mathrm{T}$ and tumor cells and exert promising antitumor activity. ${ }^{27}$

\section{Conclusion}

Chitosan-based nanoparticles for dsNKG2D-IL-21 fusion gene delivery exert promising effects on lymphocyte activation and tumor growth suppression. The easy generation, good biosafety, and tumor-centered biodistribution of dsNKG2D-IL-21 plasmid chitosan nanoparticles suggest that these nanoparticles could be potentially used for tumor therapy in clinics.

\section{Acknowledgments}

This work was supported by the National Natural Science Foundation (nos 81671547, 81471547, 81273214, and 81172785 ) of China and the social development fund of Yangzhou municipality (YZ2014179).

\section{Author contributions}

GW conceived and designed the research; LT conducted most of the research; All authors contributed toward data analysis, drafting and critically revising the paper and agree to be accountable for all aspects of the work.

\section{Disclosure}

The authors report no conflicts of interest in this work.

\section{References}

1. Sim GC, Radvanyi L. The IL-2 cytokine family in cancer immunotherapy. Cytokine Growth Factor Rev. 2014;25(4):377-390.

2. Floros T, Tarhini AA. Anticancer cytokines: biology and clinical effects of interferon- $\alpha$, Interleukin (IL)-2, IL-15, IL-21, and IL-12. Semin Oncol. 2015;42(4):539-548.

3. Tian Y, Zajac AJ. IL-21 and T cell differentiation: consider the context. Trends Immunol. 2016;37(8):557-568.

4. Al-Chami E, Tormo A, Khodayarian F, Rafei M. Therapeutic utility of the newly discovered properties of interleukin-21. Cytokine. 2016;82(6): 33-37.

5. Tangye SG. Advances in IL-21 biology - enhancing our understanding of human disease. Curr Opin Immunol. 2015;34(3):107-115.
6. Leonard WJ, Wan CK. IL-21 signaling in immunity. F1000Res. 2016; 5.pii: F1000 Faculty Rev-224.

7. Chávez-Blanco A, Chacón-Salinas R, Dominguez-Gomez G, et al. Viral inhibitors of NKG2D ligands for tumor surveillance. Expert Opin Ther Targets. 2016;20(11):1375-1387.

8. Lanier LL. NKG2D receptor and its ligands in host defense. Cancer Immunol Res. 2015;3(6):575-582.

9. Cerqueira BB, Lasham A, Shelling AN, Al-Kassas R. Nanoparticle therapeutics: technologies and methods for overcoming cancer. Eur $J$ Pharm Biopharm. 2015;97(Pt A):140-151.

10. Zhao PL, Zhao YJ, Leng J, Gong WJ. [Study of NK cell activation by colon cancer cells genetically modified with NKG2D-IL-21 fusion gene ex vivo]. J Clin Med in Practice. 2016;20(1):1-4. Chinese.

11. Hu H, Yu L, Tan S, Tu K, Wang LQ. Novel complex hydrogels based on N-carboxyethyl chitosan and quaternized chitosan and their controlled in vitro protein release property. Carbohydr Res. 2010;345(4): 462-468.

12. Wu J, Wei W, Wang LY, Su ZG, Ma GH. A thermosensitive hydrogel based on quaternized chitosan and poly (ethylene glycol) for nasal drug delivery system. Biomaterials. 2007;28(13):2220-2232.

13. Ma HL, Whitters MJ, Konz RF, et al. IL-21 activates both innate and adaptive immunity to generate potent antitumor responses that require perforin but are independent of IFN-gamma. J Immunol. 2003; 171(2):608-615.

14. Wang G, Tschoi M, Spolski R, et al. In vivo antitumor activity of interleukin 21 mediated by natural killer cells. Cancer Res. 2003;63(24): 9016-9022.

15. Brady J, Hayakawa Y, Smyth MJ, Nutt SL. IL-21 induces the functional maturation of murine NK cells. J Immunol. 2004;172(4):2048-2058.

16. Nakano $\mathrm{H}$, Kishida $\mathrm{T}$, Asada $\mathrm{H}$, et al. Interleukin-21 triggers both cellular and humoral immune responses leading to therapeutic antitumor effects against head and neck squamous cell carcinoma. $J$ Gene Med. 2006;8(1):90-99.

17. Davis MR, Zhu Z, Hansen DM, Bai Q, Fang Y. The role of IL-21 in immunity and cancer. Cancer Lett. 2015;358(2):107-114.

18. Søndergaard H, Skak K. IL-21: roles in immunopathology and cancer therapy. Tissue Antigens. 2009;74(6):467-479.

19. Saade F, Petrovsky N. Technologies for enhanced efficacy of DNA vaccines. Expert Rev Vaccines. 2012;11(2):189-209.

20. Bertrand N, Wu J, Xu X, Kamaly N, Farokhzad OC. Cancer nanotechnology: the impact of passive and active targeting in the era of modern cancer biology. Adv Drug Deliv Rev. 2014;66(1):2-25.

21. Liu BS, Stoop JN, Huizinga TW, Toes RE. IL-21 enhances the activity of the TLR-MyD88-STAT3 pathway but not the classical TLRMyD88-NF- $\kappa B$ pathway in human B cells to boost antibody production. J Immunol. 2013;191(8):4086-4094.

22. Li SN, Wang W, Fu SP, et al. IL-21 modulates release of proinflammatory cytokines in LPS-stimulated macrophages through distinct signaling pathways. Mediators Inflamm. 2013;2013:548073.

23. Schmidt SR. Fusion-proteins as biopharmaceuticals-applications and challenges. Curr Opin Drug Discov Devel. 2009;12(2):284-289.

24. Lichtor T, Glick RP. Immunogene therapy. Adv Exp Med Biol. 2012; 746:151-165.

25. Huergo-Zapico L, Acebes-Huerta A, Gonzalez-Rodriguez AP, et al. Expansion of NK cells and reduction of NKG2D expression in chronic lymphocytic leukemia. Correlation with progressive disease. PLoS One. 2014;9(10):e108326.

26. Roshani R, Boroujerdnia MG, Talaiezadeh AH, Khodadadi A. Assessment of changes in expression and presentation of NKG2D under influence of MICA serum factor in different stages of breast cancer. Tumour Biol. 2016;37(5):6953-6962.

27. Zhang T, Sentman CL. Cancer immunotherapy using a bispecific NK receptor fusion protein that engages both $\mathrm{T}$ cells and tumor cells. Cancer Res. 2011;71(6):2066-2076. 
International Journal of Nanomedicine

Dovepress

\section{Publish your work in this journal}

The International Journal of Nanomedicine is an international, peerreviewed journal focusing on the application of nanotechnology in diagnostics, therapeutics, and drug delivery systems throughou the biomedical field. This journal is indexed on PubMed Central, MedLine, CAS, SciSearch ${ }^{\circledR}$, Current Contents ${ }^{\circledR} /$ Clinical Medicine,
Journal Citation Reports/Science Edition, EMBase, Scopus and the Elsevier Bibliographic databases. The manuscript management system is completely online and includes a very quick and fair peer-review system, which is all easy to use. Visit http://www.dovepress.com/ testimonials.php to read real quotes from published authors.

Submit your manuscript here: http://www.dovepress.com/international-journal-of-nanomedicine-journal 